\title{
Towards User-generated Microgames for Supporting Learning: An Investigative Exploration
}

\author{
Imam Fitri Rahmadi \\ Universitas Pamulang, Indonesia \\ ORCID: 0000-0001-5175-1187 \\ Zsolt Lavicza \\ Johannes Kepler Universität Linz, Austria \\ ORCID: 0000-0002-3701-5068 \\ Tony Houghton \\ Johannes Kepler Universität Linz, Austria \\ ORCID: 0000-0002-2899-3310
}

Received: 8 Sep 2020

Accepted: 25 Dec 2020

\begin{abstract}
Educational games have great potential for learning, however the potential of user-generated microgames for supporting learning is still not completely understood. The present study reviews the design quality of user-generated microgames based on microgame design fundamentals and explores the potential of the games for facilitating learning from the perspective of elementary teachers in terms of the strengths, weaknesses, opportunities, and threats. This is exploratory research organised within the GeoGebra application and with the participation of elementary teachers in Indonesia. The study found that the games met the microgame design fundamentals but the mechanics and aesthetics were in need of some improvements. The major strength of the games is simplicity for learning, however their user interfaces are their major weakness. Learning resources and environments in Indonesian elementary schools are relatively supportive of games integration into learning processes whilst senior teachers and rural areas are less so. These findings suggest users should pay more attention to audios, visuals and special effects as well as winning conditions when creating microgames in open platforms. It is of pivotal importance to provide playing instructions and games that fit to mobile screens. Furthermore, teachers have to carefully select the games and consider the context before utilising user-generated microgames for assisting learning.
\end{abstract}

Keywords: user-generated microgames, microgame-based learning, microgame design fundamentals, exploratory study

\section{INTRODUCTION}

Educational games have great potential for supporting learning, however the potential of user-generated microgames is not yet completely understood. Although some studies about microgames for learning exist (e.g., Bellotti et al., 2004; Brom et al., 2011, 2015; Lukosch et al., 2016), they work with microgames created by publishers or paid professionals instead of microgames created by users. User-generated microgames are now increasingly available due to the popularity of open learning platforms that allow users develop their own games such as GeoGebra, PurposeGames, and Scratch. 
The evidence of learning through games has already been shown in professional learning games. Playing educational games boosts learning performances, improves cognitive skills, and can be more effective than conventional media for learning (Mayer, 2016, 2019). Additionally, integrating games into learning processes increases learner motivation and completion rates as well as widening participation, stimulating collaborative learning, and improving learning efficacy (de Freitas, 2006). Playing games for learning results in a range of perceptual, cognitive, behavioral, affective, and motivational impacts and outcomes (Connolly et al., 2012). However, their integration into formal teaching and learning processes remains an issue. According to Brom et al. (2011), this is one classical problem on the integration of more general serious games for learning in schools that is somehow always more problematic than that of for training in workplaces.

A variety of constraints arise on the implementation of game-based learning by virtue of various reasons including but not limited to long-duration gameplay and minimum of adequate technologies (Rice, 2007), lack of teachers innovativeness and best practices (Ketelhut \& Schifter, 2011), and limited games that match to learning objectives (Watson \& Yang, 2016). Teachers may not be able to practice game-based learning with general educational games since they have a very strict and limited time. Furthermore, they do not have time to create their own games as well. Working with user-generated microgames that have very shortduration gameplay and available freely online, therefore, appears feasible as the solution. It does not take a whole learning session but can also be easily found as well as integrated into learning and instruction processes in the classroom. Meanwhile, further exploration is still needed to prove the potential of usergenerated games to support learning.

Several studies have suggested that further exploring games for learning is of importance to provide more rigorous evidence of their effectiveness. It is essential to develop a better understanding of the tasks, activities, skills, and operations that different kinds of games could offer and examine how these might match desired learning outcomes (Connolly et al., 2012). How to appropriately design and implement games for instructional purposes is also a basic research issue and a gap in current knowledge (Garris et al., 2002). Furthermore, the usefulness of educational games could not be reconciled by a single study thus studying other microgames for learning is needed (Brom et al., 2011). The present study supports and continue the long tradition of research in the area of game-based learning.

The novelty of this study is twofold. First, the study takes educational microgames as very simple games lasting in minutes rather than regular learning games that take a relatively long duration to play. Microgames could provide brief engagement and meaningful experience in learning. Second, the microgames involved in this study were generated by users in open platforms rather than produced by paid professionals or publishers. It was very interesting to examine games that were created, shared, and used by regular people simultaneously without any commercial motives. Overall, user-generated microgames might be the trend in the future.

\section{THEORETICAL FRAMEWORK}

The theoretical framework relies on the theories of user-generated content and microgames in education. In addition, microgame design fundamentals were formulated as a conceptual framework to examine the design quality of user-generated microgames.

\section{User-Generated Microgames}

The term user-generated microgames consists of two terminologies: user-generated content and microgames. User-generated content (UGC) can be simply defined as media content generated or created by users. Neither publishers nor paid professionals, the content comes from regular people who voluntarily contribute data and information in texts, sound, images, and videos primarily distributed through the Internet (Daugherty et al., 2008; Krumm et al., 2008). Furthermore, users may also modify, share, and consume content simultaneously in individual or collaborative ways (Smith et al., 2012). The emergence of Web 2.0 and prominently UGC platforms such as wikis, blogs, forums, and social media open the possibility 
of web users to be producers and consumers at the same time (Kaplan \& Haenlein, 2010; van Dijck, 2009), which is so-called prosumers (Toffler, 1980).

Microgames are often associated with board games such as Checkers, Cluedo, and Tic-tac-toe and simple digital minigames series like Super Smash Bros, Wario Land, and Super Mario. In an educational setting, however, the games have been defined as relatively simple computer games that are easy to play for defined goals in a short game-play (Brom et al., 2011). For training in the workplace context, microgames are defined as simulation games that can be played in a short time period imitating a specific problem in the organization (Lukosch et al., 2016). Both definitions consider the short duration game-play as one of the characteristics of microgames. The word micro illustrates that microgames consist of micro-content (Hug, 2005), thus as in microlearning, it should be integrated into the meso and macro structures of learning (Kapp \& Defelice, 2019, p. 13-16). The use of games specifically for educational purposes so-called serious games (Richey, 2013: p. 86) provide learners with fun and meaningful experiences resulting in higher motivation and performances (Dörner et al., 2016).

Based on the definition of user-generated content and microgames, for the purpose of this study, usergenerated microgames are defined as very simple games created by users that provide brief engagement and meaningful experience directed to a specific objective for supporting learning and instruction integrated with existing resources in various environments. The definition illustrates microgames characteristics namely simple, brief, meaningful, specific, and integrated. Users, in this study, are the users of GeoGebra, a dynamic mathematics software for all levels of education that brings together geometry, algebra, spreadsheets, graphing, statistics and calculus in one easy-to-use package (About GeoGebra, 2020). There are numerous user-generated microgames in GeoGebra that might be beneficial for supporting mathematics teaching and learning in primary, secondary, and post-secondary education. The games could be freely modified, shared and used by students, teachers, and general users for educational purposes integrated with lesson plans, course material, syllabus, and curriculum already exist in the regular classroom.

\section{Microgame Design Fundamentals}

Four basic elements of games called elemental tetrad have been proposed by Schell (2008) to help game designers create professional entertainment games. These interrelated elements are mechanics, aesthetics, story, and technology and they contribute equally to the game design processes. This framework followed by Kalmpourtzis (2018) added one more element called pedagogy in terms of designing appropriate educational games, making an elemental pentad. Pedagogy plays a central element that game designers should focus on the development of games for educational purposes. The description of the five basic educational game elements (Kalmpourtzis, 2018; Schell, 2008) is presented in Table 1.

Table 1 describes the five basic educational game elements. None of the elements is more important than the others (Schell, 2008), although in the learning or serious games development, pedagogy is the center element that influences the other elements (Kalmpourtzis, 2018). There are debates in which serious games should be design based on pedagogical or entertainment elements. Focusing on pedagogical elements to design learning games is in line with Susi et al. (2007), and de Freitas and Liarokapis (2011, p. 13) argued that serious games focus on the important elements of learning while entertainment games focus on the important aspects of fun. 
Table 1. The description of the five basic educational game elements

\begin{tabular}{ll}
\hline Basic Elements & Descriptions \\
\hline Mechanics & Mechanics refer to a set of rules and procedures that regulate players in achieving game objectives. \\
& This element includes game rules, number of players, interactions between players and the game, \\
& winning conditions, and any other essential elements related to the game logic. Mechanics is what \\
& makes game different compared to more linear entertainment experiences such as books and \\
& movies. \\
& Aesthetics relate to how the game overall environment looks, sounds, smells, tastes, and feels. This \\
Aesthetics & element includes visuals, audios, symbols, styles, effects, and other aesthetical elements that have \\
& the most direct relationship to the player's experiences. To get the player's experience and fully \\
& immersed in games, the aesthetics should be reinforced by relevant mechanics, story, and \\
& technology. \\
Story refers to a series of events from the beginning to the ending. It may be a linear, nonlinear, or \\
spatial sequence of connected events that unfolds in the game. This element should be also \\
connected with mechanics, aesthetics, and technology to help game designers create the intended \\
experiences. Games can tell stories but also stories can be created through the player's interactions \\
with games. \\
Technology represents a set of tools, resources, and other technical aspects to run the game. This \\
element does not exclusively refer to high technology, but to any materials and interactions that \\
make a game possible such as papers and pencils, plastic chits, or high-powered lasers. The \\
technology in games enables players to do certain things and prohibits from doing the other ones. \\
Pedagogy refers to learning aspects that inevitable in educational games. The aspects include \\
learning objectives, contents, and activities as well as learning methods, approaches, and theories \\
underlying the game development. There is an option for the combination of whether pedagogy is \\
adjusted to existing games or the other elements are adjusted to predefined pedagogy elements.
\end{tabular}

Figure 1 illustrates the conceptual framework of microgame design fundamentals adapted from Schell (2008), and Kalmpourtzis (2018). The framework shows that microgames should have simple mechanics, meaningful aesthetics, brief story, integrated technology, and specific pedagogy. In addition, pedagogy is in the center thus the other elements should be adjusted according to predefined pedagogy elements. The elements of technology are least visible to the players whilst mechanics, pedagogy, and story are located at the medium level of visibility, and the elements of aesthetics are at the most visible ones. Appropriate design of user-generated microgames should meet this framework to be potentially used for educational purposes.

In addition to the basic game elements, Schell (2008) also considers the visibility gradient to show that technological elements are least visible to the players while mechanics and story are somewhere in the middle, and aesthetical aspects are the most visible ones. The concept of basic game elements for entertainment and education is useful to formulate microgame design fundamentals. Therefore, adapted from the elemental tetrad and elemental pentad, this study formulates a conceptual framework of microgame design fundamentals by adding the characteristics of microgames. This framework is used for examining the design quality of user-generated microgames in this study. 


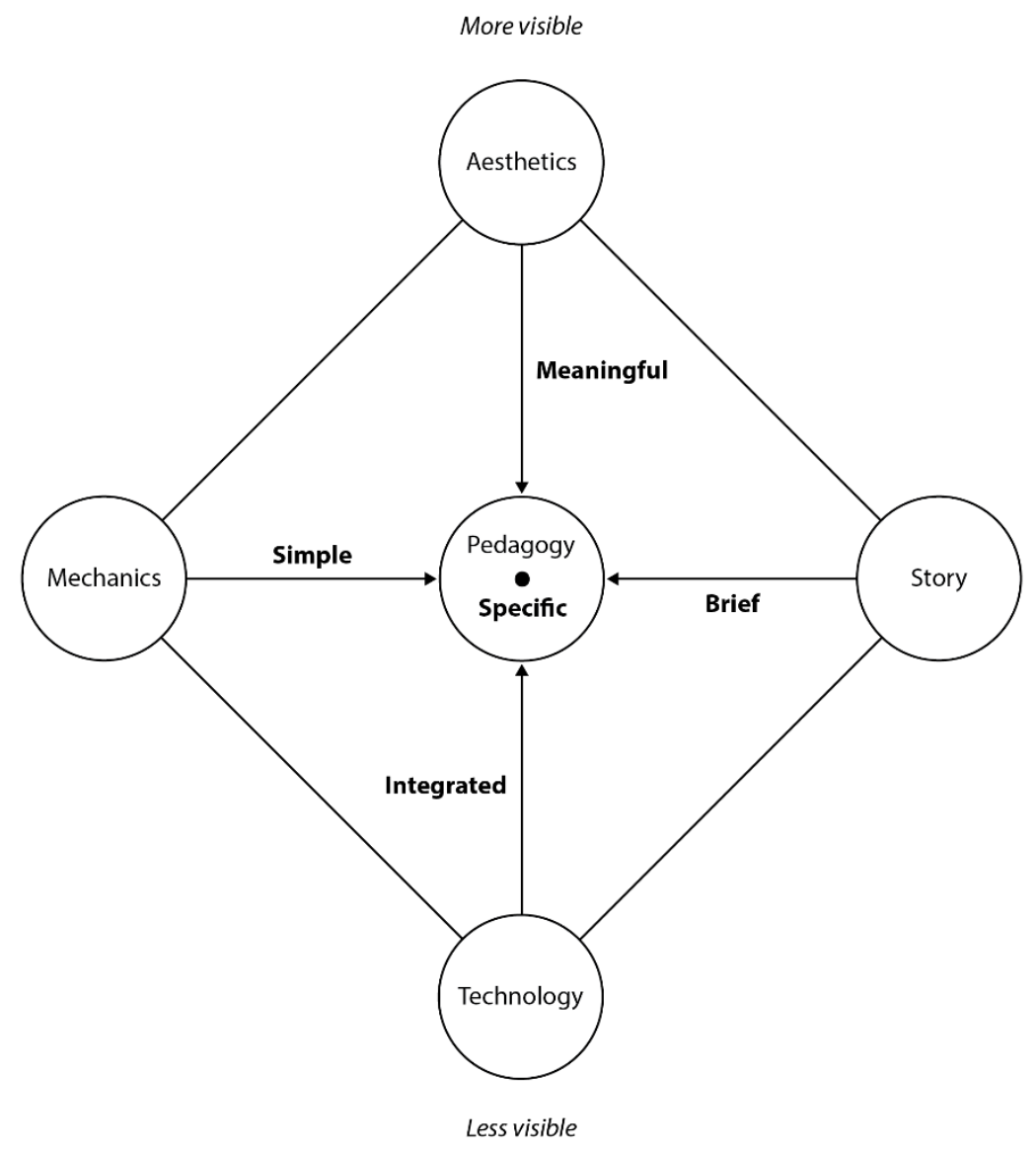

Figure 1. The conceptual framework of microgame design fundamentals

\section{LITERATURE REVIEW}

The utilisation of user-generated microgames for learning has not been greatly explored in existing studies. Previous studies about educational microgames worked with games created by publishers and paid professionals. Brom et al. $(2011,2015)$ examined the effectiveness of the Orbis Pictus Bestialis microgame to engage students and for knowledge acquisition as well as whether Emil and Bird Breeder microgames are best to play individually or collaboratively at high schools. The findings show that harnessing the games in formal school environments looks promising to be played individually or collectively for supplementing, reinforcing, and integrating knowledge acquired in the lesson. However, microgames in the present study are naturally designed by users in their own styles so exploring those games may lead to different results.

Previous research has also investigated the integration of microgames into the workplace and the general environment. Lukosch et al. (2016) employed the Yard Crane Scheduler microgame for training-based situated learning in the workplace. It is recognised as a novel approach towards situated and experiential learning that can be highly engaging for workforce training. Bellotti et al. (2004) studied VeGame (standing for Venice Game), which is a series of very small games played by the general public to gain a better understanding and appreciation of cultural heritage around the city of Venice. The study concluded that educational territorial microgames appeal and are effective to attract players providing an active and engaging experience in cultural activities. The games in both studies appear to be carefully designed by professionals with flawless elements while in the present study the design elements of user-generated microgames may not be as complete as those professionally-designed microgames. Therefore, it is pivotal to understand to what extend microgames created by users have the potential for supporting learning.

Although extensive research has been carried out on the implementation of user-generated content in various disciplines including education, no single study exists which adequately covers user-generated 
content applications on microgames for learning. The existing studies focus on user-generated content for regular serious games, in particular toward its mechanics. A study by Hicks et al. (2014) found that usergenerated educational games suffer a serious problem regarding the low quality of content, and employing a self-evaluation appears to be a solution to control and reduce the number of low-quality serious games. In addition, users pay less attention to the game level creations and learning objectives, thus providing an easyto-use feature for creating games promotes the game affordance (Hicks et al., 2016). Another study proposes the use of social gaming mechanics for user-generated learning games in order to keep students involved in the game to practice and refine their skills continuously (Hicks, 2012). Further, multiplayer games could provide a rich learning environment during the gameplay (Casey et al., 2007). This study investigates further not only the mechanics but also all other elements including aesthetics, story, technology, and most importantly pedagogy.

The other studies investigated the effect of user-generated content on serious games. Adding user-generated content to educational games increases the player's attractiveness and creativity as well as enhances the replayability of the games (Boyce et al., 2011). In addition, the ability to create user own content in educational games also effective for motivating users to use and reuse the open game-creator platforms (Boyce et al., 2012). In general, user-generated content evidently fruitful to enrich the gamer's experiences (Ahmad et al., 2010). Meanwhile, the studies have not further discussed the way they integrate the games in learning. Rather than investigating the effect, it is hence critical to see in advance how to design and integrate user-generated microgames appropriately for learning.

Many studies investigating the value of games focus on learning improvement from specific game features, learning acquisition from playing games, and comparing games with other traditional media for learning (Mayer, 2014). The present study falls into the second category that is exploring the value of user-generated microgames for knowledge acquisition. Hence, this study reviews the design quality of user-generated microgames based on the microgame design fundamentals and explores the potential of the microgames for supporting learning from the perspective of elementary teachers in terms of their strengths, weaknesses, opportunities, and threats.

\section{METHOD}

This exploratory study was conducted within the GeoGebra application with the participation of elementary teachers in Indonesia. It is an investigative exploration (Stebbins, 2001) as an inquisitive process about usergenerated microgames for facilitating mathematics learning particularly in elementary schools. The exploration aims to review the design quality of user-generated microgames and explore elementary teacher perspectives towards the games for supporting learning. This would provide the basis and direction of future research and indeed, such a further activity is outlined in a later section.

An online observation was conducted to review the user-generated microgames design quality based on microgame design fundamentals. There are nine microgames at various school levels randomly selected from GeoGebra. The microgame design fundamentals, as mentioned in the theoretical framework, were adapted from Schell (2008), and Kalmpourtzis (2018) as a framework to examine the microgames design quality. Results of the observation were analysed descriptively to simplify, analyse, and describe the key features of the data (Holcomb, 2016).

The exploration of elementary teacher perspectives of user-generated microgames for learning was organised by using a semi-structured in-depth online interview that focused on its strengths, weaknesses, opportunities, and threats for supporting mathematics learning in elementary schools. Three elementary teachers were selected with regard to their school locations including urban, suburb, and rural areas. Prior to the interview, they were invited to try the first selected three games created by users on the GeoGebra for elementary schools. An open coding (Glaser, 2016) was employed to analyse the interview results. 
Table 2. The selected user-generated microgames from GeoGebra

\begin{tabular}{|c|c|c|c|c|}
\hline User-generated Microgames & School Levels & Genres & Topics & Key math skills \\
\hline 1. Mazze 16 - Pikachu & Elementary & Strategy & Logic & Spatial sense \\
\hline \multicolumn{5}{|l|}{ Creator: oliv053c (2016) } \\
\hline \multicolumn{5}{|l|}{ Link: https://www.geogebra.org/m/wAAbd4JB } \\
\hline 2. Fit the Four Pieces & Elementary & Puzzle & Logic & Spatial sense \\
\hline Creator: Diego Lieban (2019) & & & Square & \\
\hline \multicolumn{5}{|l|}{ Link: https://www.geogebra.org/m/d4hsce9f } \\
\hline 3. Spaceship Racing & Elementary & Racing & Addition & Number sense \\
\hline Creator: cemccourseware (2016) & & & Integers & \\
\hline Link: https://www.geogebra.org/m/qJR8EbT2 & & & Subtraction & \\
\hline 4. Proof Without Words & Middle & Simulation & Geometry & Representation \\
\hline Creator: Steve Phelps (2015) & & & Pythagoras & \\
\hline Link: https://www.geogebra.org/m/ZFTGX57r & & & Pythagorean theorem & \\
\hline 5. Introduction to Sine & Middle & Simulation & Sine & Measurement \\
\hline Creator: GeoGebra Institute of Hong Kong \& & & & Trigonometry & \\
\hline \multicolumn{5}{|l|}{ Alex CHIK (2013) } \\
\hline \multicolumn{5}{|l|}{ Link: https://www.geogebra.org/m/epjHMJr5 } \\
\hline 6. Linear Equations - Super Mario Brothers & Middle & Strategy & Equations & Problem-solving \\
\hline Creator: hackingmaths (2012) & & & Linear equations & \\
\hline \multicolumn{5}{|l|}{ Link: https://www.geogebra.org/m/AddsY7EP } \\
\hline 7. Quadratic Equations - Super Mario Brothers & High & Strategy & Equations & Problem-solving \\
\hline Creator: hackingmaths (2012) & & & Quadratic equations & \\
\hline \multicolumn{5}{|l|}{ Link: https://www.geogebra.org/m/fGnx52K4 } \\
\hline 8. Log War & High & Strategy & Logic & Estimation \\
\hline \multicolumn{5}{|l|}{ Creator: John Golden (2015) } \\
\hline \multicolumn{5}{|l|}{ Link: https://www.geogebra.org/m/g36WySNY } \\
\hline 9. Lights Out & High & Puzzle & Logic & Pattern \\
\hline \multicolumn{5}{|l|}{ Creator: Dimitris Mirogiannis (2013) } \\
\hline Link: https://www.geogebra.org/m/xY6xKPWg & & & & \\
\hline
\end{tabular}

\section{RESULTS AND DISCUSSION}

A plethora of user-generated microgames is available in GeoGebra that might be valuable to support mathematics learning at all levels of education. After randomly selecting nine microgames from the category of elementary, middle, and high schools in GeoGebra, theirs design qualities was reviewed based on microgame design fundamentals. Table 2 presents the selected games with further details.

Table 2 presents the selected user-generated microgames from GeoGebra with more detailed information about its genres, topics, and key math skills. The genres of the microgames include strategy, puzzle, simulation, and racing. Each game has a specific topic such as logic, square, addition, integers, substraction, geometry, pythagoras, sine, and equations. Furthermore, the games address particular key math skills: spatial sense, number sense, representation, measurement, problem-solving, estimation, and pattern.

Following up on the review, three elementary teachers were selected for an interview in order to explore their perspective of user-generated microgames for supporting mathematics learning particularly in elementary schools. They have been invited and tried the first selected three games for elementary schools prior to the interview. Table 3 depicts the detail of the teacher's profiles.

Table 3 shows the profiles of teachers who participated in this study. There were a male teacher aged 30 and two females teachers age 29 years. All teachers hold a bachelor degree in education and have experience in teaching practices for around 5 to 10 years. The teachers teach at the class of III and V (8-9 and 10-11 age groups) at public elementary schools in urban, suburb, and rural areas of Indonesia. The different settings were chosen to cover the very different educational environments in the country and to set the scope for further studies. 
Table 3. The profile of interviewed teachers

\begin{tabular}{lccccccc}
\hline Teachers & Gender & Age & Education & Experience & Class & School & Location \\
\hline T1 & Male & 30 & Bachelor & $5-10$ years & V & Public & Urban \\
T2 & Female & 29 & Bachelor & $5-10$ years & III & Public & Suburb \\
T3 & Female & 29 & Bachelor & 5-10 years & V & Public & Rural \\
\hline
\end{tabular}

Table 4. The one-on-one reviews of user-generated microgames design

\begin{tabular}{|c|c|c|c|c|c|c|c|}
\hline \multicolumn{2}{|c|}{ Microgames } & \multirow{2}{*}{$\begin{array}{c}\text { Mechanics: } \\
\text { Simple } \\
\text { Yes }\end{array}$} & \multirow{2}{*}{$\begin{array}{l}\text { Aesthetics: } \\
\text { Meaningful } \\
\text { Yes }\end{array}$} & \multirow{2}{*}{$\begin{array}{c}\text { Story: Brief } \\
\text { Yes }\end{array}$} & \multirow{2}{*}{$\begin{array}{c}\text { Technology: } \\
\text { Integrated } \\
\text { Yes }\end{array}$} & \multirow{2}{*}{$\begin{array}{l}\text { Pedagogy: } \\
\text { Specific } \\
\text { Yes }\end{array}$} & \multirow{2}{*}{$\begin{array}{l}\text { Specific Remarks } \\
\text { No instructions, } \\
\text { sounds \& effects }\end{array}$} \\
\hline 1. & Mazze 16 - Pikachu & & & & & & \\
\hline 2. & Fit the Four Pieces & Yes & Yes & Yes & Yes & Yes & $\begin{array}{l}\text { No instructions, } \\
\text { sounds \& effects }\end{array}$ \\
\hline 3. & Spaceship Racing & Yes & Yes & Yes & Yes & Yes & $\begin{array}{c}\text { No sounds \& } \\
\text { effects }\end{array}$ \\
\hline 4. & Proof Without Words & Yes & Yes & Yes & Yes & Yes & $\begin{array}{l}\text { No instructions, } \\
\text { sounds \& effects }\end{array}$ \\
\hline 5. & Introduction to Sine & Yes & Yes & Yes & Yes & Yes & $\begin{array}{l}\text { No instructions, } \\
\text { sounds \& effects }\end{array}$ \\
\hline 6. & $\begin{array}{l}\text { Linear Equations - } \\
\text { Super Mario Brothers }\end{array}$ & Yes & Yes & Yes & Yes & Yes & $\begin{array}{c}\text { No sounds \& } \\
\text { effects }\end{array}$ \\
\hline 7. & $\begin{array}{l}\text { Quadratic Equations - } \\
\text { Super Mario Brothers }\end{array}$ & Yes & Yes & Yes & Yes & Yes & $\begin{array}{c}\text { No sounds \& } \\
\text { effects }\end{array}$ \\
\hline 8. & Log War & Yes & No & Yes & Yes & Yes & $\begin{array}{l}\text { No instructions, } \\
\text { sounds \& effects }\end{array}$ \\
\hline 9. & Lights Out & Yes & Yes & Yes & Yes & Yes & $\begin{array}{c}\text { No sounds \& } \\
\text { effects }\end{array}$ \\
\hline
\end{tabular}

Results of the study presented are based on the main research aims that are to review the design quality of user-generated microgames and to explore the potential of the microgames for supporting learning from the perspective of elementary teachers viewed on its strengths, weaknesses, opportunities, and threats.

\section{The Design Quality of User-generated Microgames}

According to the framework of microgame design fundamentals, user-generated microgames design should have simple mechanics, meaningful aesthetics, brief story, integrated technology, and specific pedagogy. The framework underlies the reviews, which are presented in Table 4.

Table 4 outlines the design quality of user-generated microgames that have been reviewed one-by-one based on microgame design fundamentals. Overall, the vast majority of the games have met the microgame design fundamentals with minor exceptions. Only the Log War does not have meaningful aesthetics in the design. The common drawbacks are absence of games instructions and that all the games are silent without any sounds and visuals effects.

Table $\mathbf{4}$ focuses on the design quality of each game while a more general and descriptive review is needed to delineate the trend. This is provided in Table 5.

Table 5 summaries the user-generated microgames design general reviews based on microgame design fundamentals. The games already have simple mechanics but suffer under weak winning conditions. They by far have meaningful aesthetics, although there are no audios and special effects and drawn in twodimensional (2D) graphics. All the games contain linear stories and their technology requires integration to meso and macro level of learning. The games have specific pedagogy with certain learning contents and activities that promote certain skills in mathematics but not all the games are directly related to learning objectives. 
Table 5. The general reviews of user-generated microgames design

\begin{tabular}{|c|c|}
\hline Design Fundamentals & General Reviews \\
\hline Simple mechanics & $\begin{array}{l}\text { The selected user-generated microgames from GeoGebra have relatively simple game rules } \\
\text { and are a single-player game. Doing small tasks is the interaction between players and } \\
\text { games. The winning conditions during and at the end of the game-play seem weak. }\end{array}$ \\
\hline Meaningful aesthetics & $\begin{array}{l}\text { The selected user-generated microgames from GeoGebra have relevant visuals and symbols } \\
\text { with regard to games content. Audios and special effects do not available in the games. All } \\
\text { games in two-dimensional (2D) art styles. }\end{array}$ \\
\hline Brief story & $\begin{array}{l}\text { The selected user-generated microgames from GeoGebra have a fairly brief story with linear } \\
\text { sequences. There is no story in the games with a nonlinear or spatial sequence due to its } \\
\text { brief character. }\end{array}$ \\
\hline Integrated technology & $\begin{array}{l}\text { The selected user-generated microgames from GeoGebra are in need of integration to lesson } \\
\text { plans, course materials, syllabus, and curriculum already exist in the regular classroom to } \\
\text { effectively run the games for learning. }\end{array}$ \\
\hline Specific pedagogy & $\begin{array}{l}\text { The selected user-generated microgames from GeoGebra have certain learning contents and } \\
\text { activities. Besides, some games promote key skills in mathematics. Not all the games thus } \\
\text { directly related to learning objectives. }\end{array}$ \\
\hline
\end{tabular}

The mechanical elements of the user-generated microgames are very simple. It may be simpler than those of microgames produced by publishers or paid professionals and regular serious games. Small single-player activities could be recognised as typical game-play of the games. Unfortunately, users who created the games seem to pay little attention to winning conditions. This issue in line with the study finding of Hicks et al. (2016) which revealed that users have less attention to level creations when creating user-generated educational games. As a consequence to promote games affordance, providing a user-friendly feature for creating games in open platforms is critical. Another solution is to implement social gaming mechanics (Hicks, 2012) so the winning condition naturally but continuously emerges from the user's interactions during playing. However, it does not mean the mechanics of user-generated microgames have to be complex. It is good to keep the games easy to be directly played with no pre-required knowledge and skills.

Aesthetical elements of the user-generated microgames appear relatively meaningful rather than fun. Meaningful aesthetics may differentiate educational games from the entertainment ones. Although serious games have shared components and other design issues with leisure games (Michael \& Chen, 2005, p. 43; Mildner \& 'Floyd' Mueller, 2016, p. 60), the sense of learning should be the focus of learning games (de Freitas \& Liarokapis, 2011, p. 13; Susi et al., 2007). For the aesthetics of educational user-generated microgames, therefore, it is not necessary to have astonishing audios, visuals, and special effects as far as it is relevant for learning. A balanced mixture of learning and leisure elements presents to the games a sense of edutainment so they provide fun and meaningful experiences simultaneously that may enhance learner's motivations and performances (Dörner et al., 2016).

Linear sequences dominated the brief story in the user-generated microgames, meaning that the story is simple, straightforward and focused with kind of a pithy involvement lasting in minutes. The word brief here is more appropriate for expressing conciseness rather than short because no definite number of minutes is universally acknowledged for the short duration of microgames. For instance, the Orbis Pictus Bestialis microgame has a 20-minute gameplay (Brom et al., 2011) and it is twice as long as the Yard Crane Scheduler (Lukosch et al., 2016) whilst plenty small games in GeoGebra last different time frames. Apart from the duration, it is important to keep the games as simple, straightforward, and focused as possible for a more powerful engagement.

The user-generated microgames evidently are not a complete learning ecosystem and wholesale replacement for other learning initiatives so their use for educational purposes should be attached to the existing complete system of instructions. Microgames are one of the microlearning media, thus as far as microlearning is concerned, harnessing the games for learning has to be integrated into the meso and macro structures of learning in formal, informal or non-formal means (Kapp \& Defelice, 2019, p. 13-16). This issue has to be taken into consideration more seriously in the matter of microgames development and implementation. Educational games need to be easily integrated into existing lesson plans and course 
material because they are best viewed as a teaching tool and not substitutes for teachers, trainers, or educators in general (Michael \& Chen, 2005, p. 43).

Regarding the most important elements of educational games, the pedagogy of the user-generated microgames is specific on certain learning contents and skills within focused activities. The word micro illustrates that microgames consist of micro-content (Hug, 2005). It means a very small content for more individualized learning structured by learning objects (Hug \& Friesen, 2007). The content might be adjusted based upon the abilities and interests of each learner to tailor more personalized learning with respect to their different needs, for example in mathematics learning where the micro aspects might be illustrated by learning a number or formula. Since the activities sometimes mainly promote mathematical skills, the games do not relate to learning objectives in a direct way. The content of user-generated microgames depends on the users who created the games, they freely fill in their games with specific learning materials, skills, or something else. Some rules to create content might be provided by the open platform developers, however it should not limit creativity (Boyce et al., 2012). Further, teachers who wish to integrate the games for learning are required to carefully consider the game with respect to main learning objectives.

Overall, the user-generated microgames design on GeoGebra hence so far has met the microgame design fundamentals. However, some design elements have to be enhanced particularly toward the mechanical and aesthetical components. Users should pay more attention to audios and visuals as well as the winning conditions when creating microgames in open platforms. Meanwhile, the games are not necessary to be complex and perfect as far as they have easy-to-play mechanics and meaningful aesthetics beneficial for supporting learning. Linear sequences of the game stories made it simple, straightforward, and focused resulting in more concise player engagement. Integration is of pivotal importance in the matter of microgames development and implementation that should be taken into account for whoever wishes to create and utilise user-generated microgames for learning purposes. The user-generated microgames have a micro content structure that may freely consist of certain learning materials or skills. Therefore, educators should carefully consider the pedagogical elements before using the games for learning.

\section{Teacher Perspectives of User-generated Microgames for Supporting Learning}

The exploration of teacher perspectives was conducted to gain a deeper understanding of the user-generated microgames potential for supporting learning. Opinions from the teachers complement the microgame design reviews and further predict the possibility of the games to be appropriately integrated for learning in elementary schools. The interviews with the elementary teachers run surprisingly well resulting in interesting arguments as presented in Table 6. 
Table 6. The teacher perspectives of user-generated microgames for learning

\begin{tabular}{|c|c|c|}
\hline Components & Questions & Answers \\
\hline Strengths & $\begin{array}{l}\text { What are the strengths of } \\
\text { the user-generated } \\
\text { microgames for learning } \\
\text { mathematics in elementary } \\
\text { schools? }\end{array}$ & $\begin{array}{l}\text { T1 \& T2: the games can be played either on smartphones or laptops } \\
\text { T2 \& T3: the games motivate students to compete with others } \\
\text { T1 \& T3: the games are simple and interesting } \\
\text { T1 \& T3: the short game duration encourage students to replay the games } \\
\text { T3: the games support learning processes in elementary schools }\end{array}$ \\
\hline Weaknesses & $\begin{array}{l}\text { What are the weaknesses of } \\
\text { the user-generated } \\
\text { microgames for learning } \\
\text { mathematics in elementary } \\
\text { schools? }\end{array}$ & $\begin{array}{l}\text { T2: the games are in English } \\
\text { T1, T2, \& T3: the games' interface is less attractive due to the small and } \\
\text { simple design that does not show at full screen and has no image or } \\
\text { sound effects } \\
\text { T3: the games are confusing because there are no playing instructions } \\
\text { T2: the games do not directly relate to the learning objectives }\end{array}$ \\
\hline Opportunities & $\begin{array}{l}\text { What factors support the } \\
\text { use of user-generated } \\
\text { microgames for learning } \\
\text { mathematics in elementary } \\
\text { schools? }\end{array}$ & $\begin{array}{l}\text { T2 \& T3: there are already some projectors in schools } \\
\text { T1 \& T2: there is already an opportunity to bring smartphones and } \\
\text { laptops to schools by approval from school principals and parents } \\
\text { T1 \& T3: the current curriculum support game-based learning method } \\
\text { T3: the junior teachers are usually in favour of learning by games }\end{array}$ \\
\hline Threats & $\begin{array}{l}\text { What factors inhibit the use } \\
\text { of user-generated } \\
\text { microgames for learning } \\
\text { mathematics in elementary } \\
\text { schools? }\end{array}$ & $\begin{array}{l}\text { T2: not all students or parents have a smartphone or laptop } \\
\text { T1: not all teachers, especially the senior ones, agree with the use of } \\
\text { smartphones in schools } \\
\text { T3: not all parents agree with the use of smartphones for learning in } \\
\text { homes or schools } \\
\text { T2: there is no adequate Wi-Fi at schools } \\
\text { T1 \& T3: senior teachers reluctant to learn new ways of teaching } \\
\text { T1 \& T3: not all regions in Indonesia have a good internet network } \\
\text { T3: particularly in rural areas, there is limited digital equipment at schools }\end{array}$ \\
\hline
\end{tabular}

Table 6 reveals the potential of user-generated microgames for supporting learning from the perspectives of elementary teachers viewed on its strengths, weaknesses, opportunities, and threats. On the one hand, the games are simple and interesting to be played either on smartphones or laptops to support learning processes in elementary schools. Their short durations encourage students to replay the games. Furthermore, the games motivate students to compete with others. On the other hand, there is a lack of good user interfaces. For example, the games are less attractive due to the small and simple design that does not show at full screen and has no image or sound effects. It also sometimes confusing because there are no playing instructions. Another drawback is that the games do not directly relate to learning objectives. Additionally, English as the language of the games is also considered as the weakness owing to the language of instruction in Indonesian elementary schools is Bahasa Indonesia.

There are clear opportunities to integrate user-generated microgames for supporting learning in elementary schools of Indonesia. Nowadays, elementary schools in Indonesia have been equipped with smart technologies at least such as projectors. Moreover, there is already an opportunity to bring smartphones and laptops to schools by approval from school principals and parents. The current curriculum called Kurikulum 2013 supports game-based learning and junior teachers are usually in favour of learning by games. Conversely, some threats inevitably come from students, teachers, and parents with regard to the Indonesian context. Not all students or parents have a smartphone or laptop. Teachers, especially the senior ones, do not all agree with the use of smartphones in schools, and at the same time, they are reluctant to learn new ways of teaching. Some parents also do not agree with the use of smartphones for learning in homes or schools. Respecting the broad area of Indonesia, not all regions have a good Internet network particularly in rural areas, the digital equipment is limited and no adequate $\mathrm{Wi}-\mathrm{Fi}$ at schools.

The main advantage of user-generated microgames for learning is the simplicity of the games. It is interesting to be played and replayed in smartphones, laptops, and other digital devices within a short duration. This potential in line with Bellotti et al. (2004), Brom et al. (2011, 2015), and Lukosch et al. (2016) stated that microgames appeals for learning in their research context. In particular, this supports the consideration of 
Brom et al. (2011) studying microgames for learning in schools because they are playable within school lessons with a fixed duration and match parts of the curriculum. The Van Rosmalen et al. (2014) study also chose microgames as the games fit easily into the curriculum and allow players to quickly go through the main challenges. At the same time, the current finding refuses a general impression that games require complex technologies and is difficult to organise and to embed in a curriculum (Klopfer et al., 2009). Nevertheless, it was not surprising if the games motivate students because motivation is one of the most common variables of game value for learning (Connolly et al., 2012).

On the other hand, user-generated microgames have a major disadvantage on their interfaces. The design does not fit the screen, has no image and sound effects as well as missing of playing instructions. This finding confirms the result of the games design quality review, which also found that there are no audios, visuals, and special effects in the games. The absence of playing instructions is such a serious problem as it plays a pivotal role to show how the gameplay looks like and it highly impacts cognitive processes in a learning context (Erhel \& Jamet, 2016). Therefore, users should provide clear instructions to their created games. It could be goal-oriented instructions: mastery goals and performance goals (Pintrich, 2000) or structured playing instructions (Naugle et al., 2019) respecting the learning needs and objectives. While it may be a less critical issue, the games do not always relate to learning objectives. As mentioned before, all games do not necessarily direct to learning objectives as in the curriculum since it can also focus on developing skills rather than mastering new knowledge. The language barrier seems to be a common issue in global platforms so that the teacher could mediate student's comprehension of the games.

Learning resources and environments in Indonesian elementary schools are relatively supportive towards the integration of user-generated microgames into learning processes. Initiatives to bring technology in hand to the formal schooling environment started from the implementation of a computer-based national examination that inevitably made school stakeholders harness computers in the test (Retnawati et al., 2017). Kurikulum 2013 that was widely implemented at the beginning of 2014 promotes active and scientific approaches to learning (Suyanto, 2018). It is very positive to know that junior teachers are favorable and open-minded to explore recent technologies in the classroom. They are agents of change in the adaptation and adoption of new pedagogy into teaching and learning practices.

Multiple stakeholders and local circumstances may challenge the use of user-generated microgames for supporting learning in the classroom. Indonesia as a developing country still has a problem with access to technology. Although over $90 \%$ of the adult population in Indonesia carries at least a mobile device and $60 \%$ of them are smartphones (Kemp, 2020) it happens much less in urban areas. Access to avant-garde technology remains a challenge in rural areas, in particular for Internet penetration is slower than in urban or suburban areas of Indonesia (Kurniawan \& Wartika, 2012). The condition gets worse with the fact that some parents and senior teachers seem unwilling to welcome innovations. According to Rogers (1962), they could be categorised as laggard or at least late majority in being more likely to refuse something new around them. Educating about the potential of the latest technologies for learning might be a solution to change their perceptions and beliefs (Chen, 2008; Goos \& Bennison, 2008).

To put it in a nutshell, the utilisation of user-generated microgames has many benefits and drawbacks as well as great opportunities and challenges. The implication is two-fold for users who created the games and teachers. First, users should pay more attention to mechanical and aesthetical elements when creating microgames, in particular of providing playing instructions and creating games that responsive to the screen. Second, teachers have to deal with various style of microgames as well as contextual challenges to utilise digital games for learning in the classroom, having a wide selection.

\section{LIMITATIONS}

The present study has a number of limitations. Firstly, it is limited to the view of the researcher as a reviewer based on an initial conceptual framework of microgames design fundamentals. Therefore, future work will need to validate the framework as well as review microgame design qualities from varied views, such as asking teachers or students in the targeted context. The next study will confirm or otherwise the finding of 
Hicks et al. (2014), who stated that user-generated educational games commonly have a low quality of content and another solution is needed which goes beyond employing a self-evaluation on the open platforms. Secondly, the interview was conducted with a small number of teachers at elementary schools in Indonesia. The next study will explore another perspective from different school levels and across nations, and in this direction we have collected data from an online workshop for Southeast Asian elementary teachers. It was participated by 45 teachers and 33 of them replied to our online questionnaire about their preferences in using user-generated microgames for supporting learning. A separate paper will be written from the results. Finally, this study was a first step and furthermore in-depth investigation may also be conducted such as having more experimental and collaborative research with teachers to try user-generated microgames with their students.

\section{CONCLUSION}

The present study has explored user-generated microgames for facilitating learning. In this exploration, the aims were to review the design quality of user-generated microgames based on microgame design fundamentals and to explore the potential of the microgames for supporting learning from the perspective of elementary teachers. The study has found that the game design has so far met the microgame design fundamentals, but its mechanics and aesthetics must be improved. Additionally, microgames made by users have benefits and drawbacks as well as shared opportunities and challenges for supporting learning. The findings of this study suggest that users should pay more attention to audios, visuals, and special effects as well as the winning conditions when creating microgames in open platforms. However, the games do not have to be complex and perfect, indeed they should be easy-to-play and meaningful for learning. Furthermore, it is a pivotal importance to provide playing instructions and creating responsive games. Respecting educators who wish to integrate user-generated microgames for learning, they have to carefully select the games and consider contextual circumstances. The current findings add to a growing body of literature on microgame-based learning and serve as a base for future studies.

Author contributions: All authors were involved in concept, design, collection of data, interpretation, writing, and critically revising the article. All authors approve final version of the article.

Funding: The present work is part of PhD research funded by the Indonesia-Austria Scholarship Programme (IASP), a joint scholarship between the Indonesian Ministry of Education and Culture (KEMDIKBUD) and Austria's Agency for Education and Internationalisation (OeAD-GmbH) in cooperation with ASEAN European Academic University Network (ASEA-UNINET).

Declaration of interest: Authors declare no competing interest.

Acknowledgements: The authors would like to acknowledge elementary teachers in Indonesia who voluntarily participated in the present study.

Data availability: Data generated or analysed during this study are available from the authors on request.

\section{REFERENCES}

About GeoGebra. (2020, January 14). GeoGebra. Retrieved from https://www.geogebra.org/about

Ahmad, M. (2020). Categorizing Game Design Elements into Educational Game Design Fundamentals. In I. Deliyannis (Ed.), Game Design and Intelligent Interaction (pp. 1-17). IntechOpen. https://doi.org/10.5772/intechopen.89971

Ahmad, S., Bouras, C., Hamzaoui, R., Papazois, A., Perelman, E., Shani, A., Simon, G., \& Tsichritzis, G. (2010). The community network game project: Enriching online gamers experience with user generated content. CONTENT 2010: Second International Conference on Creative Content Technologies, 2, 1-6. Retrieved from https://hal.archives-ouvertes.fr/hal-00632788

Bellotti, F., Berta, R., De Gloria, A., Ferretti, E., \& Margarone, M. (2004). Microgames for a compelling interaction with the cultural heritage. Archives \& Museum Informatics, 2, 1-16. 
Boyce, A., Campbell, A., Pickford, S., Culler, D., \& Barnes, T. (2012). Maximizing learning and guiding behavior in free play user generated content environments. Proceedings of the 17th ACM Annual Conference on Innovation and Technology in Computer Science Education, 17, 10-15. https://doi.org/10.1145/2325296.2325303

Boyce, A., Doran, K., Campbell, A., Pickford, S., Culler, D., \& Barnes, T. (2011). Social user generated content's effect on creativity in educational games. Proceedings of the 8th ACM Conference on Creativity and Cognition, 8, 317-318. https://doi.org/10.1145/2069618.2069675

Brom, C., Levčík, D., Buchtová, M., \& Klement, D. (2015). Playing educational micro-games at high schools: Individually or collectively? Computers in Human Behavior, 48, 682-694. https://doi.org/10.1016/j.chb.2015.02.025

Brom, C., Preuss, M., \& Klement, D. (2011). Are educational computer micro-games engaging and effective for knowledge acquisition at high-schools? A quasi-experimental study. Computers \& Education, 57(3), 1971-1988. https://doi.org/10.1016/j.compedu.2011.04.007

Casey, S., Kirman, B., \& Rowland, D. (2007). The gopher game: A social, mobile, locative game with user generated content and peer review. Proceedings of the International Conference on Advances in Computer Entertainment Technology, 7, 9-16. https://doi.org/10.1145/1255047.1255050

Chen, C.-H. (2008). Why Do Teachers Not Practice What They Believe Regarding Technology Integration? The Journal of Educational Research, 102(1), 65-75. https://doi.org/10.3200/JOER.102.1.65-75

Connolly, T. M., Boyle, E. A., MacArthur, E., Hainey, T., \& Boyle, J. M. (2012). A systematic literature review of empirical evidence on computer games and serious games. Computers \& Education, 59(2), 661-686. https://doi.org/10.1016/j.compedu.2012.03.004

Daugherty, T., Eastin, M. S., \& Bright, L. (2008). Exploring Consumer Motivations for Creating User-Generated $\begin{array}{llll}\text { Content. Journal of Interactive } & \text { Advertising, }\end{array}$ https://doi.org/10.1080/15252019.2008.10722139

de Freitas, S. I. (2006). Using games and simulations for supporting learning. Learning, Media and Technology, 31(4), 343-358. https://doi.org/10.1080/17439880601021967

de Freitas, S., \& Liarokapis, F. (2011). Serious games: A new paradigm for education? In Serious games and edutainment applications (pp. 9-23). Springer. https://doi.org/10.1007/978-1-4471-2161-9_2

Deliyannis, I. (Ed.). (2020). Game Design and Intelligent Interaction. IntechOpen. https://doi.org/10.5772/intechopen.77403

Dörner, R., Göbel, S., Effelsberg, W., \& Wiemeyer, J. (2016). Introduction. In R. Dörner, S. Göbel, W. Effelsberg, \& J. Wiemeyer (Eds.), Serious Games (pp. 1-34). Springer International Publishing. https://doi.org/10.1007/978-3-319-40612-1_1

Erhel, S., \& Jamet, E. (2016). The effects of goal-oriented instructions in digital game-based learning. Interactive Learning Environments, 1744-1757. https://doi.org/10.1080/10494820.2015.1041409

Garris, R., Ahlers, R., \& Driskell, J. E. (2002). Games, Motivation, and Learning: A Research and Practice Model. Simulation \& Gaming, 33(4), 441-467. https://doi.org/10.1177/1046878102238607

Glaser, B. G. (2016). Open coding descriptions. Grounded Theory Review, 15(2), 108-110.

Goos, M., \& Bennison, A. (2008). Surveying the technology landscape: Teachers' use of technology in secondary mathematics classrooms. Mathematics Education Research Journal, 20(3), 102-130. https://doi.org/10.1007/BF03217532 
Hicks, A. (2012). Creation, evaluation, and presentation of user-generated content in community game-based tutors. Proceedings of the International Conference on the Foundations of Digital Games, 12, 276-278. https://doi.org/10.1145/2282338.2282397

Hicks, A., Cateté, V., \& Barnes, T. (2014). Part of the game: Changing level creation to identify and filter low quality user-generated levels. Proceedings of the 9th International Conference on the Foundations of Digital Games, 9, 1-8.

Hicks, D., Liu, Z., Eagle, M., \& Barnes, T. (2016). Measuring Gameplay Affordances of User-Generated Content in an Educational Game. Proceedings of the 9th International Conference on Educational Data Mining, 9, 78-85. https://eric.ed.gov/?id=ED592703

Holcomb, Z. (2016). Fundamentals of Descriptive Statistics. Routledge. https://doi.org/10.4324/9781315266510

Hug, T. (2005). Micro Learning and Narration. The Proceedings of Fourth Media in Transition Conference, 113.

Hug, T., \& Friesen, N. (2007). Outline of a microlearning agenda. Didactics of Microlearning. Concepts, Discourses and Examples, 15-31.

Kalmpourtzis, G. (2018). Educational Game Design Fundamentals: A journey to creating intrinsically motivating learning experiences. CRC Press. https://doi.org/10.1201/9781315208794

Kaplan, A. M., \& Haenlein, M. (2010). Users of the world, unite! The challenges and opportunities of Social Media. Business Horizons, 53(1), 59-68. https://doi.org/10.1016/j.bushor.2009.09.003

Kapp, K., \& DeFelice, R. (2019). Microlearning: Short and sweet. ATD Press.

Kemp, S. (2020). Digital 2020: Indonesia. DataReportal - Global Digital Insights. Retrieved from https://datareportal.com/reports/digital-2020-indonesia

Ketelhut, D. J., \& Schifter, C. C. (2011). Teachers and game-based learning: Improving understanding of how to increase efficacy of adoption. Computers \& Education, 56(2), 539-546. https://doi.org/10.1016/j.compedu.2010.10.002

Klopfer, E., Osterweil, S., \& Salen, K. (2009a). Moving learning games forward. Cambridge, MA: The Education Arcade.

Klopfer, E., Osterweil, S., \& Salen, K. (2009b). Moving learning games forward. The Education Arcade. Retrieved from https://hal.archives-ouvertes.fr/hal-00593085

Krumm, J., Davies, N., \& Narayanaswami, C. (2008). User-Generated Content. IEEE Pervasive Computing, 7(4), 10-11. https://doi.org/10.1109/MPRV.2008.85

Kurniawan, A., \& Wartika, E. (2012). Evaluation of access technology to speed-up Internet penetration in remote areas, case study: Community access point in Regency of Garut, West Java, Indonesia. 2012 7th International Conference on Telecommunication Systems, Services, and Applications (TSSA), 351355. https://doi.org/10.1109/TSSA.2012.6366081

Lukosch, H., Kurapati, S., Groen, D., \& Verbraeck, A. (2016). Microgames for Situated Learning: A Case Study in Interdependent Planning. Simulation \& Gaming, 47(3), 346-367. https://doi.org/10.1177/1046878116635468

Mayer, R. E. (2014). Computer games for learning: An evidence-based approach. The MIT Press. https://doi.org/10.7551/mitpress/9427.001.0001

Michael, D. R., \& Chen, S. L. (2005). Serious games: Games that educate, train, and inform. Muska \& Lipman/Premier-Trade. 
Mildner, P., \& 'Floyd’ Mueller, F. (2016). Design of Serious Games. In R. Dörner, S. Göbel, W. Effelsberg, \& J. Wiemeyer (Eds.), Serious Games (pp. 57-82). Springer International Publishing. https://doi.org/10.1007/978-3-319-40612-1_3

Naugle, K. E., Carey, C., Ohlman, T., Godza, M., Mikesky, A., \& Naugle, K. M. (2019). Improving Active Gaming's Energy Expenditure in Healthy Adults Using Structured Playing Instructions for the Nintendo Wii and Xbox Kinect: Journal of Strength and Conditioning Research, 33(2), 549-558. https://doi.org/10.1519/JSC.0000000000002997

Pintrich, P. R. (2000). The Role of Goal Orientation in Self-Regulated Learning. In M. Boekaerts, P. R. Pintrich, \& M. Zeidner (Eds.), Handbook of Self-Regulation: Theory, Research, and Applications (pp. 451-502). Academic Press. https://doi.org/10.1016/B978-012109890-2/50043-3

Retnawati, H., Hadi, S., Nugraha, A. C., Arlinwibowo, J., Sulistyaningsih, E., Djidu, H., \& Apino, E. (2017). Implementing the computer-based national examination in Indonesian schools: The challenges and strategies. Problems of Education in the 21st Century, 75(6), 612-633. https://doi.org/10.33225/pec/17.75.612

Rice, J. W. (2007). New media resistance: Barriers to implementation of computer video games in the classroom. Journal of Educational Multimedia and Hypermedia, 16(3), 249-261.

Richey, R. (Ed.). (2013). Encyclopedia of terminology for educational communications and technology. Springer. https://doi.org/10.1007/978-1-4614-6573-7

Schell, J. (2008). The art of game design: A book of lenses. Elsevier/Morgan Kaufmann. https://doi.org/10.1201/9780080919171

Smith, A. N., Fischer, E., \& Yongjian, C. (2012). How Does Brand-related User-generated Content Differ across YouTube, Facebook, and Twitter? Journal of Interactive Marketing, 26(2), 102-113. https://doi.org/10.1016/j.intmar.2012.01.002

Stebbins, R. A. (2001). Exploratory research in the social sciences. SAGE. https://doi.org/10.4135/9781412984249

Susi, T., Johannesson, M., \& Backlund, P. (2007). Serious Games: An Overview (IKI Technical Reports). Institutionen för kommunikation och information. Retrieved from http://urn.kb.se/resolve?urn=urn:nbn:se:his:diva-1279

Suyanto, S. (2018). The Implementation of the Scientific Approach through 5Ms of The New Curriculum of 2013 in Indonesia. Jurnal Cakrawala Pendidikan, 37(1), Article 1. https://doi.org/10.21831/cp.v37i1.18719

Toffler, A. (1980). The third wave: The classic study of tomorrow. Bantam Books.

van Dijck, J. (2009). Users like you? Theorizing agency in user-generated content. Media, Culture \& Society, 31(1), 41-58. https://doi.org/10.1177/0163443708098245

Van Rosmalen, P., Boyle, E. A., Van der Baaren, J., Kärki, A. I., \& del Blanco Aguado, Á. (2014). A case study on the design and development of minigames for research methods and statistics. EAl Endorsed Transactions on Serious Games, 1(3), 1-9. https://doi.org/10.4108/sg.1.3.e5

Watson, W., \& Yang, S. (2016). Games in schools: Teachers' perceptions of barriers to game-based learning. Journal of Interactive Learning Research, 27(2), 153-170.

Correspondence: Imam Fitri Rahmadi, Universitas Pamulang, Indonesia. E-mail: imamrahmadi@unpam.ac.id 